PATENT CLEARANCE IS NOT REQUIRED PRIOR $\mathrm{DOE} / \mathrm{PC} / 89777--\mathrm{T} 5$

TO THE PUBLICATION OF THIS DOCUMENT

\author{
Entanced eal \\ Hydlogatification via \\ TECHNICAL PROGRESS REPORT \\ Oxidative Premreatmant. DOE Grant \#DE-FG22-89PC89777 \\ Reporting Period: 6/1/91 - 8/31/91
}

DE92 002.756

\begin{abstract}
Work during the eighth quarter of the grant period has involved rate studies of demineralized coal, low temperature reactions to investigate initial char reactivities, and oxidative treatments combined with ASA measurements to study active site concentrations during gasification and oxidations. Work completed to date was compiled and submitted in a paper to FUEL in early July, 1991.
\end{abstract}

\title{
RESULTS
}

Demineralized coal - Two procedures for coal demineralization have been conducted. Originally, coal was pyrolyzed and the resultant char then demineralized via repeated contact with $\mathrm{HF}$ and $\mathrm{HCl}$. Using this method, the lowest concentration of ash obtainable in the resulting char was about 28 by weight. It was thought that perhaps pyrolysis was making some of the ash inaccessible to the acids during treatment, or that pyrite present in the coal was not being solubilized by the acids. A second demineralization procedure was then conducted, in which the as-received coal was first demineralized by repeated contact with $\mathrm{HNO}_{3}, \mathrm{HF}$ and $\mathrm{HCl}$, and then pyrolyzed. The resulting char was then again subjected to $\mathrm{HF}$ and $\mathrm{HCl}$ acid treatment to remove any residual mineral matter. Even using this multiple-step treatment with $\mathrm{HNO}_{3}$ to remove pyrite, we were unable to attain inorganic material contents any lower than $1: 1$ wto.

Reaction rate studies of the demineralized char indicated little effect of demineralization on uncatalyzed hydrogasification rate based on carbon weight. For $\mathrm{K}_{2} \mathrm{CO}_{3}$-catalyzed hydrogasification, however, removal of ash results in strongly enhanced rate (Figure 1 ), indicating the strong deactivating effect that coal ash has on alkali carbonate catalysts.

Initial gasification rate - The apparent absence of rate enhancement following oxidative pretreatment of coal char prompted us to further investigate initial hydrogasification rates. We believed that our usual experimental techniques, which only begin to measure rate at 3-48 carbon conversion, was missing any enhancement that might occur small conversions. Two methods were used: rate measurements at lower temperatures, and rate measured by rapid exposure to hydrogen at normal gasification temperature of $725^{\circ} \mathrm{C}$.

Results of low temperature measurements are given in Figure 2. Gasification rates are very low; two-hour runs give only 1.5-38 conversion at $600^{\circ} \mathrm{C}$. Several points are of interest. First, gasification rate declines very sharply with conversion at low conversion. It is not clear at this time whether the decline in rate with conversion results from an decline in residual carbon reactivity as conversion proceeds, or from exposure to hydrogen in hydrogasification. Similar studies with steam or $\mathrm{CO}_{2}$ may provide additional insight.

Second, if the observed initial rate $\left(0.4 \mathrm{cc} \mathrm{CH}_{4} / \mathrm{min} \mathrm{gC}\right)$ at $600^{\circ} \mathrm{C}$ is normalized to $725^{\circ} \mathrm{C}$ by using the measured activation energy of $65 \mathrm{kcal} / \mathrm{gmol}$, 
the resulting normalized rates between 0.5 and 28 carbon conversion are several-fold larger than the first experimental rate measured at $725^{\circ} \mathrm{C}$ at about 38 conversion. This indicates that the initial rate measured at $725^{\circ} \mathrm{C}$ is not truly an initial rate. The normalized rate extrapolated to 38 carbon conversion is about the same as that measured at 7250 , indicating consistency in the results.

Initial gasification rate at $600^{\circ} \mathrm{C}$ is enhanced following oxidative pretreatment (Figure 2). The enhancement is moderate and only propogates to about 28 carbon conversion, and was thus not previously detected at higher temperatures. The enhancement is mild because the as-prepared char surfaces are already oxidized to a significant extent and thus are not affected by oxidation very much.

Active Surface Area (ASA) Measurements - Much effort has been expanded in this period in comparing ASA measured by oxygen chemisorption with hydrogasification rate. Initial experiments using coal char gave unexpected results, as ASA apparently increased with conversion even though gasification rate declined strongly. By subjecting a sample of coal ash alone to hydrogasification conditions and then conducting the ASA measurements on the sample, we determined that the ash was reduced during hydrogasification and then strongly adsorbed oxygen upon measurement of ASA. This gave false ASA results, and prompted us to discontinue attempts to measure ASA for samples containing inorganic matter.

Using Saran char, which contains little ash ( 0.08 wt $)$, we conducted further rate and ASA measurements. First, gasification was carried out to a desired conversion, and then a sample of the residual char was removed and analyzed via oxygen chemisorption for ASA. This procedure was repeated several times on the same sample to develop a curve of rate and ASA versus carbon conversion. Results of this experiment are shown in Table I below, in which absolute rate and rate per unit ASA are given versus conversion.

TABLE I

RATE AND ASA FOR SARAN CHAR

Conversion

(wt \& C)

$\begin{array}{ll}12.9 & 1.9 \\ 18.7 & 1.0 \\ 25.1 & 0.6 \\ 28.3 & 0.4\end{array}$

Absolute rate

(cc $\mathrm{CH}_{4} / \mathrm{min} \mathrm{gC}$ )

1.9
1.0
0.6
0.4

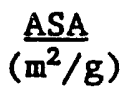

$\frac{\text { ASA }}{\left(\mathrm{m}^{2} / g\right)}$

Rate based on ASA

(cc $\mathrm{CH}_{4} / \mathrm{min} \mathrm{m}^{2} \mathrm{ASA}$ )

There is a trend in ASA that follows the decrease in hydrogasification rate with conversion, but the change in ASA is not as large as that for rate. The rate normalized to ASA changes less that absolute rate, but without question declines with conversion. Although the observed trend in ASA is encouraging, the use of oxygen chemisorption to measure ASA in hydrogasification has not yet been clearly demonstrated.

A second set of experiments was conducted in which gasification and intermittent oxidation of Saran char was conducted. Analysis of residual samples withdrawn following gasification and oxidation is currently being done to determine how ASA changes following the various treatments. ASA results obtained so far are inconclusive and are being analyzed further. 


\section{CONTINUING WORK}

Work during the remainder of the grant period will focus on completing the rate versus ASA measurements and on continuous addition of oxygen to hydrogen during gasification. It is expected that all work on the project will be completed by the end of the grant period in February, 1991.

\section{DISCLAIMER}

This report was prepared as an account of work sponsored by an agency of the United States Government. Neither the United States Government nor any agency thereof, nor any of their employees, makes any warranty, express or implied, or assumes any legal liability or responsibility for the accuracy, completeness, or usefulness of any information, apparatus, product, or bility for the accuracy, completeness, or usefulness of any information, appaty owned rights. Referprocess disclosed, or represents that its use would not to any specific commercial product, process, or service by trade name, trademark, manufacturer, or otherwise does not necessarily constitute or imply its endorsement, recommendation, or favoring by the United States Government or any agency thereof. The views and opinions of authors expressed herein do not necessarily state or reflect those of the United States Government or any agency thereof. 


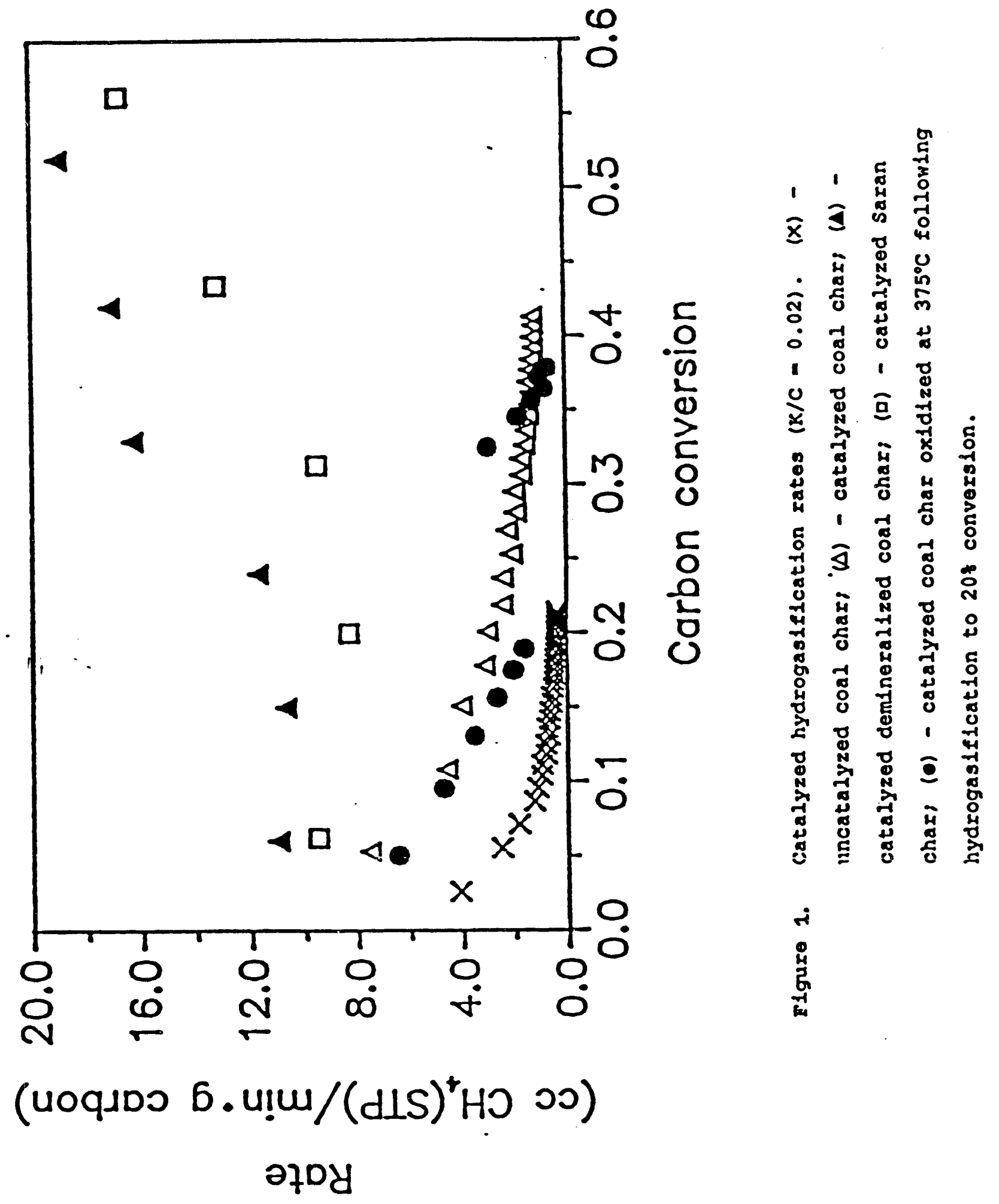




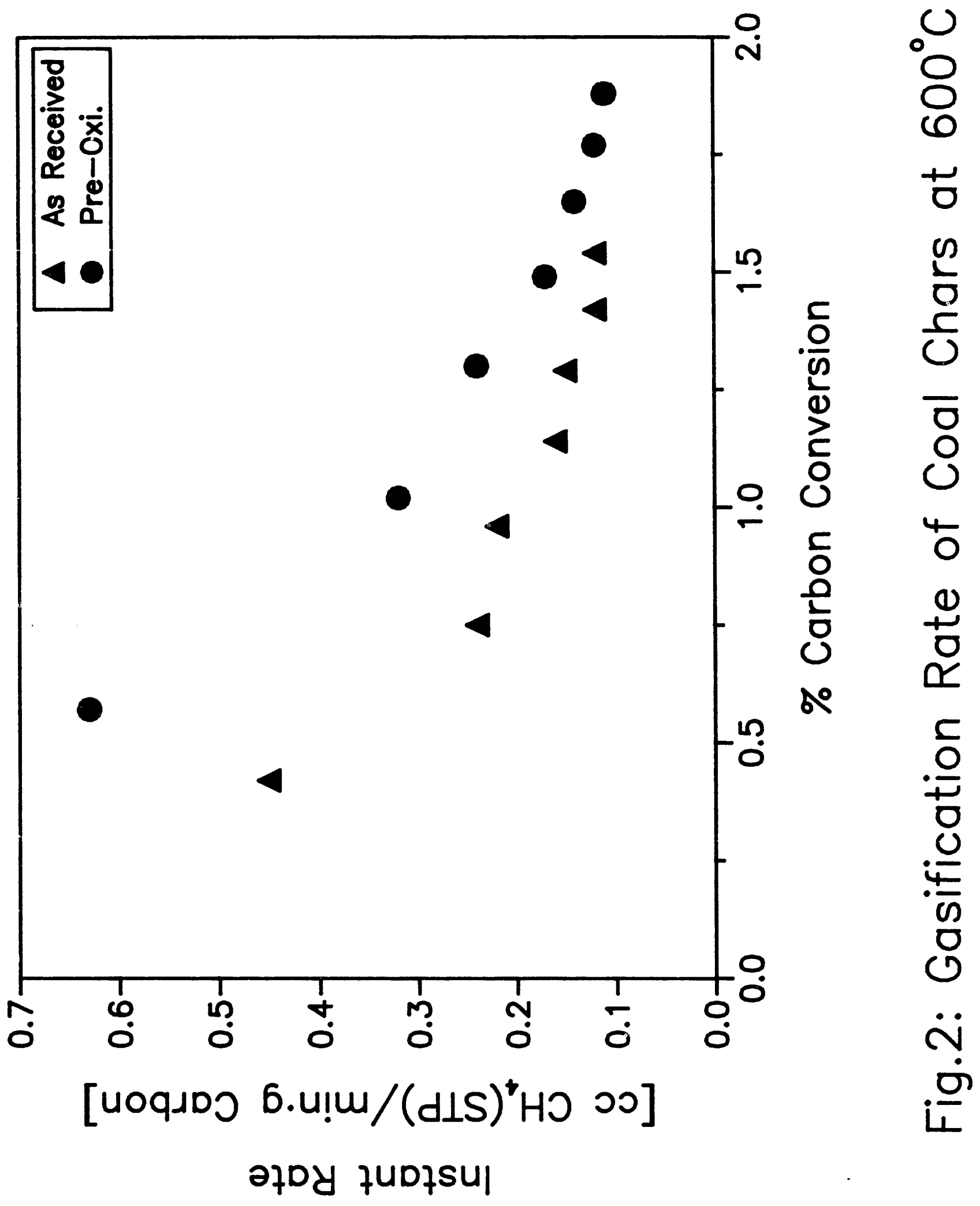



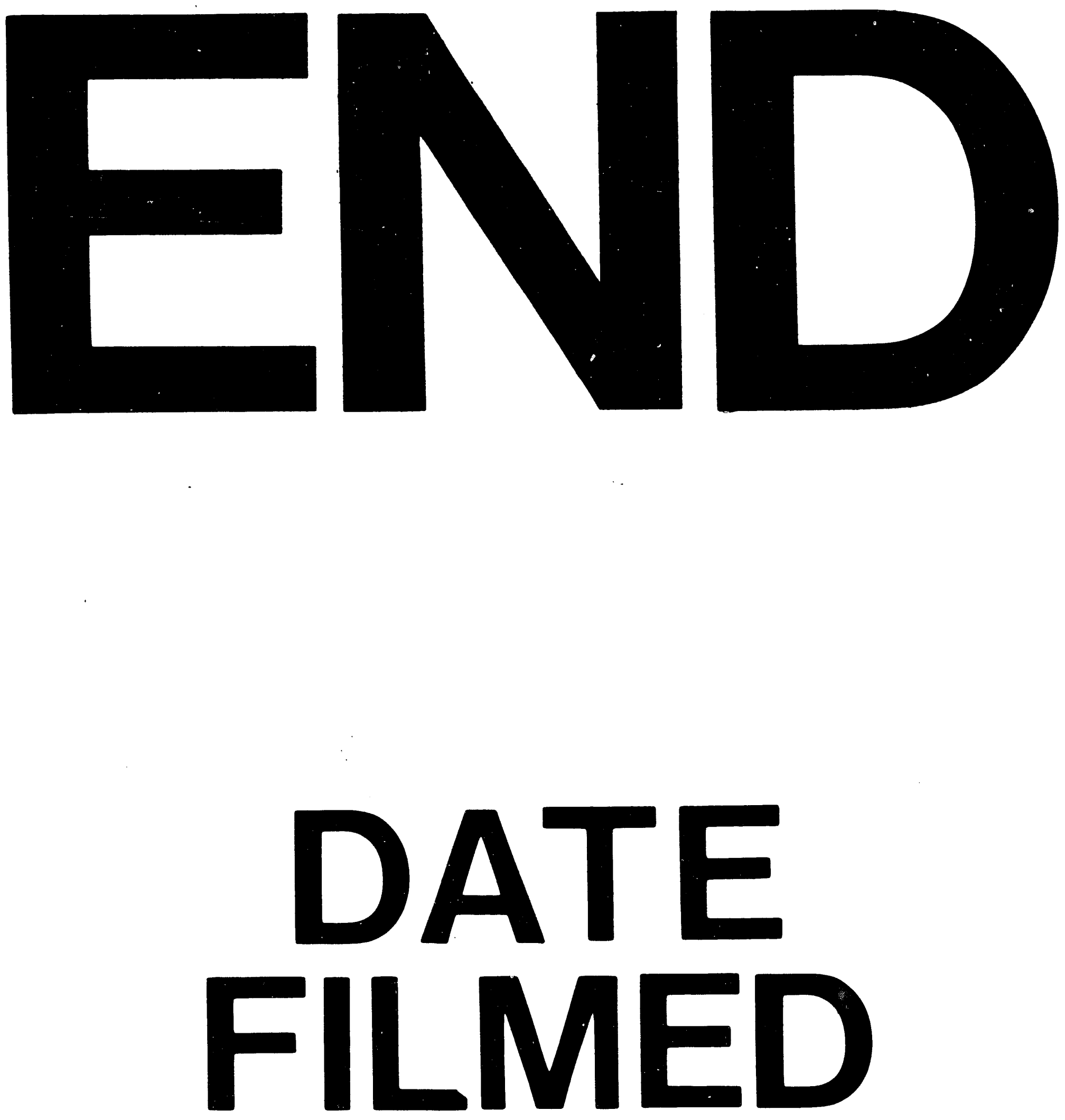

1

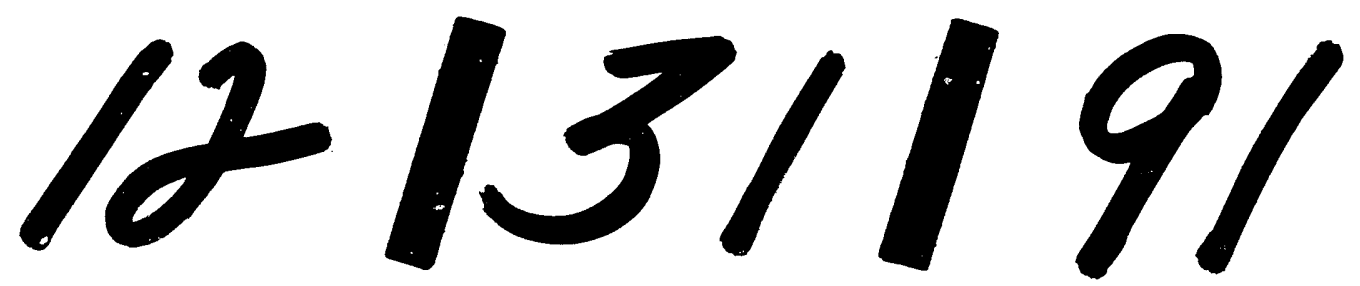




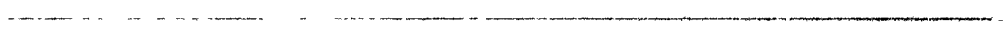

